This is an Accepted Manuscript of an article published by Taylor \& Francis in Journal of Spanish Cultural Studies on 27 Nov 2019, available online:

https://www.tandfonline.com/doi/10.1080/14636204.2019.1689705 


\title{
El género policíaco en la ficción española (1990-2010): el auge de las cadenas privadas y los valores conservadores
}

Anna Tous-Rovirosa

Departamento de Periodismo y Ciencias de la Comunicación, Universidad Autónoma de Barcelona, Bellaterra, España

\begin{abstract}
La presente investigación versa sobre los contenidos de la producción audiovisual de ficción de género policíaco emitida en España entre 1990 y 2010. Los 36 títulos del período (primordialmente series, pero también miniseries, $T V$-movies y seriales) se han analizado utilizando metodología tanto cuantitativa (reconstrucción de la parrilla televisiva) como cualitativa, prestando especial atención a los temas sociales, así como a las tramas y los estereotipos empleados. Tras una descripción de la tipología de los programas, se plantea una relación entre los valores que buscan transmitir, los resultados de audiencia, el carácter público o privado de la cadena emisora y el partido político en el Gobierno. En cuanto a los resultados, las cadenas privadas son las que emiten las series más longevas de este periodo y con mayor índice de audiencia $[E l$ comisario (Tele5, 1999-2009), Policías. En el corazón de la calle (Antena3, 20002003) y Los hombres de Paco (Antena3, 2005-2010] y son aquellas en las que los valores referentes a la migración experimentan una evolución positiva. A pesar de ello, persiste una perspectiva androcéntrica que, en algunos casos, sufre una involución a lo largo del tiempo, siendo más progresistas en lo que se refiere al tratamiento del género algunas series de los años 90 (Petra Delicado, Tele5, 1999; Pepe Carvalho, Tele5, 1999-2000) que las ya mencionadas de la década posterior.
\end{abstract}

\section{PALABRAS CLAVE}

Ficción policíaca; series españolas; neoliberalismo; ficción televisiva; estereotipos de género 


\section{Introducción}

El contexto social, político y mediático del período analizado (1990-2010) se caracteriza por la aparición en España de las televisiones privadas, el fin de los monopolios públicos en toda Europa y el inicio español de una nueva etapa de modernidad. Políticamente, se produce alternancia de los gobiernos socialistas (Felipe González, 1989-1993; 1993-1996, y José Luis Rodríguez Zapatero, 2004-2008, 20082011) y populares (José M. Aznar, 1996-2000, 2000-2004), en un contexto político dominado en la UE por directivas centradas en la liberalización del mercado audiovisual, como la denominada TV Without Frontiers (1989). La introducción de las televisiones privadas en el mercado español obedece a un talante neoliberal más propio de la UCD que del PSOE, que cede a las presiones empresariales, sociales e institucionales de la época (Rueda-Laffond y Chicharro 2006, 296). Esta época, que comienza con la aparición de las televisiones privadas tras la aprobación de la Ley de Televisión Privada (1988), y que dura hasta completarse la desregulación, se caracteriza en el ámbito mediático por la multiplicación de canales y el auge de los formatos de telerrealidad, la denominada neo-televisión, y por la llegada de los reality-shows y los talk-shows en un contexto de un incremento de competencia entre las cadenas. En cuanto a la ficción, conviven la producción propia, marcada por la comedia familiar (Diego 2010) en las televisiones públicas y privadas, con las emisiones de ficción extranjera, tanto en las mencionadas televisiones como especialmente en Cuatro. En la década de los 90, al darse por terminada la Guerra Fría, con la caída del comunismo soviético, se inicia la consolidación del neoliberalismo en el ámbito occidental. En España, la ley del divorcio había sido aprobada en 1981. El matrimonio entre personas del mismo sexo es legalizado en 2005, y en 2007 se aprueba la denominada Ley de igualdad efectiva de mujeres y hombres (Ley Orgánica 3/2007, 22 de marzo).

Los objetivos de esta investigación son, en primer lugar, reconstruir la programación de ficción televisiva española en el período 1990-2010, en particular la de ficciones de género policíaco, clasificar y describir las producciones según los formatos pertinentes y, a continuación, estudiar los valores transmitidos por ellas en lo que respecta a la representación de estereotipos. Se trata de observar los valores que trasladan dichas ficciones, así como su papel clave en cómo una sociedad se representa a sí misma. 
Respecto a los 36 títulos analizados, emitidos entre 1990 y 2010 en España (en coherencia con el proyecto en que se enmarca este trabajo), partimos de la hipótesis de que las cadenas privadas presentan valores más conservadores que las públicas (en legislaturas socialistas) en las emisiones de género policíaco, debido a lo cual se produce una involución en el tiempo de dichos valores. Dada la alternancia política de gobiernos del PSOE y el PP en el período analizado, este dato se toma también en consideración.

La metodología de análisis comprende el análisis textual (Creeber 2001), y el discourse tracking de Altheide (2000), quien propone un seguimiento exhaustivo de contenidos mediáticos para, a partir de las preguntas de investigación, plantear categorías mediante un análisis tanto textual e interpretativo como temático. La primera fase de la investigación recurre al uso de una metodología cuantitativa, de reconstrucción de la parrilla, para lo cual se emplea una ficha de análisis elaborada ad hoc por el grupo de investigación y al trabajo de búsqueda hemerográfica. El análisis comprende las producciones iniciadas hasta 2010 y que finalizan con posterioridad a esta fecha. Se han visionado los dos primeros y los dos últimos episodios de cada temporada de las distintas producciones, ya que en los primeros se establecen las bases del relato, mientras que los últimos permiten cerciorarse de cambios sorpresivos propios del género y que pueden modificar el contenido de las tramas analizadas.

El análisis se realiza a partir del concepto "conservadurismo" que se detalla a continuación. El conservadurismo es la ideología que defiende las estructuras existentes en una sociedad, opuesta normalmente a posibles cambios. Aboga por el respeto a la autoridad y las jerarquías; propugna el mantenimiento del sistema de valores políticos, sociales y morales tradicionales, y se opone a reformas o cambios radicales. Además, está vinculado con el neoliberalismo en lo que se refiere a la persistencia de la tradición y de los ámbitos de la nación, la religión y la familia (Giddens citado en Sanmartín 2007, 128). De acuerdo con estas premisas, analizamos el concepto "conservadurismo" en las categorías siguientes (ver Cuadro 1), las cuales hacen referencia a cuestiones fundamentales de la sociedad, y en particular a las relaciones entre hombre y mujer, la sexualidad, la dimensión económica (marginalidad por falta de recursos económicos), la alteridad (migración) y la representación de los cuerpos policiales. 


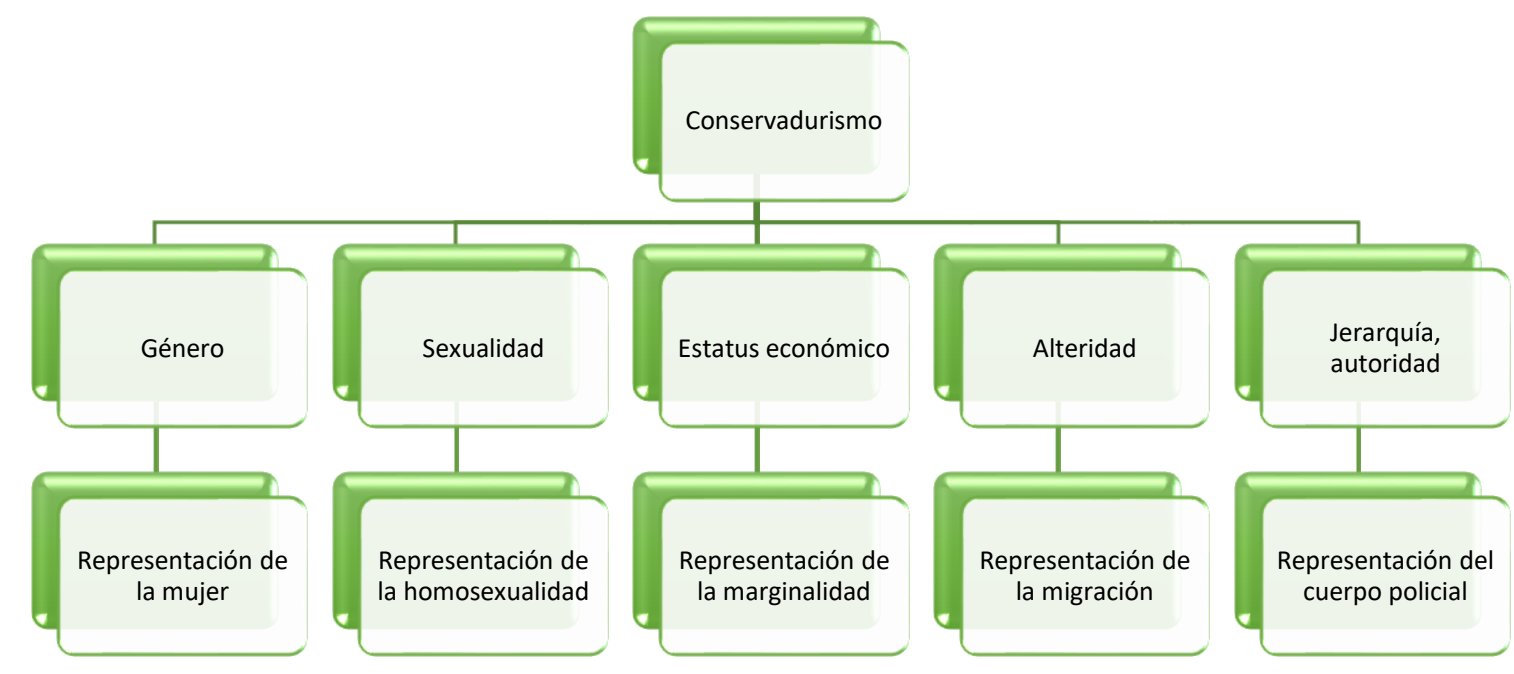

Cuadro 1: Análisis del concepto “Conservadurismo”. Elaboración propia.

En la Ficha de Análisis se detallan los ítems descriptivos que permiten analizar la representación de los distintos colectivos, en cuanto a la representación positiva y negativa de cada una de las categorías en que se agrupan y también en relación a los estereotipos, roles temáticos, axiología, origen y frames interpretativos (Lacalle 2008). Se analiza también la relevancia de los personajes y de la trama.

Se ha estudiado con anterioridad la representación de los migrantes en las series españolas (Galán 2006; Lacalle 2008); la representación de la mujer (Galán 2007; Lacalle 2016; Smith 2007; Torres 2007; Tous, Meso, Simelio 2013); de los migrantes (Lacalle 2008; Ruiz Collantes 2006; Smith 2007); y de la homosexualidad en la ficción (Benshoff y Griffin 2005; González de Garay 2012a; Melero 2012; Russo 1981; Torres 1996).

La investigación sobre género y comunicación en el ámbito de las producciones audiovisuales de ficción tiene una amplia tradición tanto en el ámbito anglosajón (Gerbner et al. 1978; Durkin 1985; Davis 1990; Geraghty 1991; Fouts y Burggraf 1999) como en el español (Aran-Ramspott et al. 2011; García-Muñoz, Fedele, Gómez-Díaz 2012; Gordillo-Álvarez, Guarinos 2010; Medina-Bravo et al. 2010; Tous-Rovirosa y Aran-Ramspott 2017). 
La categoría de análisis propia del género policíaco es la relativa a la representación de los cuerpos policiales (jerarquía/autoridad). Consideramos que es pertinente porque el género policíaco tradicionalmente cumple con la función de reforzar el statu quo (producciones conservadoras) o de denunciarlo (producciones progresistas). Entre los investigadores del género policíaco destacamos a Colmeiro (2015), Cooke (2001), Piper (2015), Smith (2007) Torrado (2017) y Turnbull (2014).

$\underline{\text { Tabla de los } 36 \text { títulos policíacos españoles (1990-2010) }}$

\section{Ficha de análisis}

\section{Descripción del género policíaco emitido en España}

El formato estrella de la ficción policiaca española del período analizado es la serie, emitida generalmente en prime-time. Tres títulos constituyen las principales referencias de este período: El comisario (Tele5, 1999-2009), Policías, en el corazón de la calle (Antena3, 2000-2003) y Los hombres de Paco (Antena3, 2005-2010). Aunque Policías es la de menor duración de las tres, es la única producción del período que cuenta con cuatro spin-offs con formato de TV-movie, tres de ellas centradas en parejas de personajes de la serie (Lucía y Carlos, Mateo y Rafa, Ferrer y Ruso) y la cuarta en el tema de las snuff movies, protagonizada por Vera. Los tres son títulos emblemáticos de las respectivas cadenas televisivas.

Las tres series mencionadas son las producciones más longevas y con mejores datos de audiencia del total de estrenos de género policíaco (36 títulos), que comprenden 24 series, 11 miniseries y TV-movies y 1 serial. La tendencia mayoritaria es la ambientación urbana (24 títulos), con una clara preeminencia de los escenarios ambientados en Madrid (14 títulos). Algunas de las miniseries están basadas en hechos reales (48 Horas, El Bloke: Coslada Cero, El caso Wanninkhoff, Fago, Soy el solitario y Una bala para el Rey). La duración predominante es de 60 minutos (Cuenta atrás, El comisario, UCO, Policías, Petra Delicado), aunque también hay producciones de 50, 70, 80 y 90 minutos. Se observa únicamente una producción de 25 minutos (el serial de 
emisión diaria Suárez y Mariscal caso cerrado). Más allá del serial, no se aprecia correlación entre la duración y el formato.

Únicamente 4 títulos son coproducciones: Alta tensión, Eurocops, Hermanos y detectives y Pepe Carvalho, casi todas con empresas europeas, italiano-francesaespañola en el caso de Pepe Carvalho ${ }^{1}$.

Se han emitido varias adaptaciones de Pepe Carvalho: la coproducción de $1986^{2}$, y la coproducción de 1999, que continuaría en 2003. Eurocops es una coproducción entre 7 cadenas europeas, que se distribuyeron los diferentes episodios para poder reflejar la idiosincrasia de cada país. Alta tensión es una coproducción de TVE, Jetfilins y Hamster, y Hermanos y detectives, española-argentina, basada en una serie original, de Telefé Contenidos, que se empezó a rodar en 2006.

La mayor parte de las ficciones están ambientadas en la "actualidad" (en referencia al momento temporal de emisión), excepto La chica de ayer, Pájaro en una tormenta (ambientada en los años 70) y Una bala para el Rey (ambientada en 1995).

Alta tensión, Camino de Santiago, Pájaro en una tormenta, Pepe Carvalho y Petra Delicado son adaptaciones literarias, un procedimiento frecuente en el género policíaco audiovisual. En otros casos, se trata de la adaptación de un formato, como la argentina Hermanos y detectives (Telefe Contenidos, 2006), RIS Científica de la italiana R.I.S._Delitti imperfetti (Canale 5, 2005-2009) y la alemana Niedrig und Kuhnt, SAT1, 2003 (Suárez y Mariscal caso cerrado). Entre los autores de las novelas de donde proceden, cabe destacar a Manuel Vázquez Montalbán (autor de las novelas de Pepe Carvalho y creador del personaje), Isaac Montero (Pájaro en una tormenta, publicada en 1984) y Alicia Giménez Barlett, creadora de Petra Delicado (10 novelas publicadas entre 1996 y 2005). También son reseñables los buenos resultados de audiencia, con un share $^{3}$ del 29,5\%, de la miniserie Camino de Santiago (Antena 3, 1999), basada en una idea original de Arturo Pérez Reverte, coautor del guión. El Bloke. Coslada Cero, que narra las acciones de un grupo de policías españoles corruptos, parte del caso policial denominado por los medios "Caso Coslada", en la Comunidad de Madrid.

Para explicar el sorpasso de la ficción policíaca española a partir del 2000, Romero $(2015,263)$ subraya la emergencia de los realities policíacos en los años noventa y el impulso dado a la producción de miniseries, telefilmes y series por la Ley General de 
Comunicación Audiovisual de 2001. Consideramos que debe añadirse como causa de este sorpasso la emisión en las cadenas nacionales de ficciones extranjeras de género policíaco con éxito de audiencia (Anuarios de GECA). Entre 2007 y 2009 tiene lugar un auge en la producción de contenidos: en dos años, todas las cadenas, públicas y privadas, emiten o comienzan a emitir 16 producciones, casi el 50\% del total de títulos divulgados entre 1990 y 2010.

Las producciones unitarias ( $T V$-movies) y las miniseries, por sus características de formato, facilitan la estructuración del relato en torno a una única línea argumental. Por ejemplo, la historia de Jaime Jiménez Arbe (Pepo Oliva) en Soy el solitario, el "ladrón de bancos más famoso de los últimos tiempos"4 perseguido por la Guardia Civil, basada en hechos reales; la desaparición de una chica en la noche de su decimoctavo cumpleaños, Desaparecida; la narración del intento de asesinato de Juan Carlos I en 1995, perpetrado por Soto, un histórico componente de ETA, en Una bala para el Rey; o el crimen familiar que conmocionó España en 1980, en El crimen de los marqueses de Urquijo. Esta última TV-movie formaba parte de una serie antológica de TVE denominada La huella del crimen, que contó con tres temporadas y cuyo objetivo era narrar los crímenes más atroces ocurridos en España, bajo la dirección e interpretación de destacados profesionales ${ }^{5}$ y mediante el uso recurrente de una voz en off: "la historia de un país es la historia de sus crímenes". El crimen de los marqueses de Urquijo, dirigida por Fernando Cámara y Pedro Costa, e interpretada por Juanjo Puigcorbé y Félix Gómez, pone de manifiesto, al igual que Una bala para el Rey, el objetivo explícito de reconstruir en la ficción televisiva una parte de la historia reciente. De hecho, todas las series policíacas españolas emitidas entre 1990 y 2010 constituyen un retrato de la época, en ocasiones realista y costumbrista (como Brigada Central, Desaparecida, El caso Wanninkhoff, Petra Delicado, Fago). Las distintas producciones analizadas establecen mecanismos para construir e interpretar el pasado, además de una perspectiva histórica del análisis televisivo (Rueda Laffond y Coronado Ruiz 2016).

\section{Tipología de programas}

Las ficciones policíacas españolas del período analizado empezaron en RTVE, que ejercía aún su monopolio en España, con Brigada central (TVE1, 1989-1992), Pájaro en una tormenta (TVE1, 1990), la coproducción Eurocops (La2, 1988-1992) y Alta 
Tensión (La2, 1993). A excepción de Robles Investigador Privado (TVE1, 2000-2001) y Mi teniente (TVE1, 2001), no será hasta 2007 (15 años después de la finalización de Brigada Central) cuando el policíaco vuelva a RTVE. Mi teniente es relevante no solo porque aparece por primera vez representada la Guardia Civil, a la que encarna la teniente aludida en el título, sino también por su escasa calidad y los pobres resultados de audiencia obtenidos. Pájaro en una tormenta se centra en un detective que intenta resolver un caso durante la transición a la democracia, enfatizando el Madrid de la época. Con Desaparecida (TVE1, 2007-2008), éxito de crítica y de audiencia, se constata en TVE la mencionada eclosión del género.

Antena3 debutó en el policíaco con la miniserie Camino de Santiago (Antena3, 1999). Policías, en el corazón de la calle es la primera producción policíaca longeva de esta cadena, junto con las mencionadas TV-movies derivadas de la serie, emitidas entre 2000 y 2001 (Lucía y Carlos, Mateo y Rafa, Ferrer y Ruso, Snuff). A continuación llegarían Antivicio (Antena3, 2000), serie de acción policial centrada en una Unidad Especial del Servicio de Inteligencia Europea que lucha contra las mafias de la Europa sin fronteras del s. XXI y la exitosa Los hombres de Paco (Antena3, 2005-2010), que superaría a Policías en número de temporadas, aunque no en audiencia. En 2005 se emite la policíaco-legal Lobos (Antena3, 2005), protagonizada por un abogado, Manuel Lobo, que se verá involucrado en una trama de narcotráfico. El cambio de día de emisión y los bajos resultados de audiencia fueron motivo para su cancelación tras 5 de los 13 capítulos de que constaba la temporada.

Tele5, en cambio, no se inicia en el género policíaco hasta la exitosa y longeva $E l$ comisario (Tele5, 1999-2009) y Petra Delicado (Tele5, 1999). RIS Científica (Tele5, 2007) completa las series policíacas de Tele5 en el período analizado. Petra Delicado, de 13 capítulos, estaba protagonizada por Ana Belén (Petra Delicado) y Santiago Segura (Fermín Garzón), y trataba de llevar a la pequeña pantalla el feminismo del personaje protagonista, una agente de policía más preocupada por la sociedad que por la delincuencia.

Otra cadena, Cuatro, se incorpora al género policíaco en 2005, el mismo año de inicio de emisiones de la cadena, con la fallida Suárez y Mariscal, caso cerrado (Cuatro, 2005), Génesis: en la mente del asesino (Cuatro, 2006-2007) y Cuenta atrás (Cuatro, 2007-2008). 


\section{Relación entre cadenas públicas y privadas, audiencia y valores transmitidos}

A continuación se describen los resultados del análisis de los 36 títulos en relación con los valores que buscan transmitir. En ocasiones anteriores hemos planteado la transmisión de valores en la ficción seriada (Tous-Rovirosa, Meso-Ayerdi, Simelio Solà 2013; Tous-Rovirosa y Aran Ramspott 2017). El estudio aborda, partiendo de las categorías propuestas, los estereotipos y su rol en la trama, la representación de la mujer, la migración, la homosexualidad, la marginalidad y los cuerpos policiales. Se pone en relación el tratamiento conservador o progresista de estas categorías en las distintas ficciones con el carácter público o privado de las cadenas emisoras, el partido político en el Gobierno y los resultados de audiencia. El análisis realizado comprende veinte años de ficción televisiva en España, diferenciados en dos períodos: 1990-2000, cuando la popularidad del género es incipiente y 2000-2010, años en los que el género adquiere una presencia real en la parrilla televisiva española, que exhibe el ya mencionado auge de ficciones policíacas seriales, y en los que la ficción nacional se impone a los realities, concretamente entre 2002 y 2006 (Diego 2010). En palabras de Vilches, Berciano y Lacalle (2000), se pasa de una "prácticamente nula tradición" del género al "Menos familia y más policía” que da título al Informe Eurofiction.

\section{Valores transmitidos}

En cuanto a los valores transmitidos por las producciones analizadas, se observa una importante diferenciación, entre las de corte más moralista y conservador (El comisario, Los hombres de Paco, ambas de la segunda década), y las más progresistas, entre las que se encuentran producciones de la primera década (Petra Delicado, Pepe Carvalho, Brigada Central) y de la segunda (Génesis, Los misterios de Laura, Desaparecida ${ }^{6}$, Policías, Cuenta atrás).

Del total de títulos (36), aproximadamente una tercera parte (14) fueron emitidos en la cadena pública y los dos tercios restantes (22), en cadenas privadas. Las series conservadoras más longevas y de más éxito se emitieron en cadenas privadas, mientras que producciones emblemáticas de corte progresista, como Brigada Central ( $1^{\text {a }}$ década), 


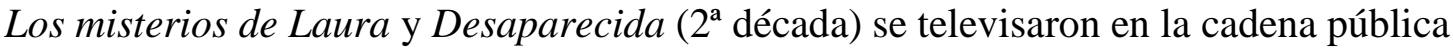
TVE1 durante las legislaturas en que gobernó el partido socialista.

Las mencionadas series conservadoras apuntan, más bien, a la perpetuación del sistema establecido (reforzar el statu quo), mientras que las progresistas muestran cierto grado de crítica social, o se observa en ellas la ausencia de tabúes referidos a temas específicos, como la sexualidad ${ }^{7}$. Héctor Ferré (Josep Maria Pou), protagonista de Policías, resume esta perspectiva en una frase, para consolar a los padres de una chica desaparecida: "Nosotros no nos dedicamos a juzgar a las personas" (“Snuff”). Corso (Dani Martín), el policía protagonista de Cuenta atrás, parte de la premisa inicial de que el suyo no es un trabajo tan fácil como "perseguir a los malos y ayudar a los buenos"8. Magalí (Alicia Bogo), en Petra Delicado, resume a la perfección el maniqueísmo propio de las producciones que refuerzan el statu quo de una sociedad, pues estas no se plantean el porqué de la delincuencia: "Yo pienso como mi padre. Aquí hay unos buenos y unos malos. Mucha caña” (“Dulce compañía”, 1.3). El comentario es relevante, aunque sea de un personaje secundario, ya que su perspectiva recibe una sanción negativa en la serie, por las implicaciones del padre de Magalí en casos de corrupción en plena transición y el uso de métodos propios del franquismo.

En general, se observa una progresión en el tratamiento de los temas analizados; pero, salvo excepciones, se produce más en superficie que en profundidad. En lo referente a la evolución y al uso de los estereotipos, cabe destacar la distinción entre series de corte conservador, como El comisario, o series más progresistas, como Génesis. En las de esta última categoría, los personajes actúan con mucha cautela para no caer en tópicos ni estereotipos ${ }^{9}$. Por el contrario, las producciones más longevas y de mayor audiencia acostumbran ser las más conservadoras.

Asimismo, es en las series más longevas y de mayor audiencia, en la segunda década analizada, y más concretamente en Los hombres de Paco y El comisario, donde persiste una perspectiva androcéntrica. El comisario es la producción más longeva y la que registra mejores resultados de audiencia, con un share de 24,5\% y más de 4 millones de espectadores de media en el período analizado (los 10 años que estuvo la serie en antena, con casi 200 capítulos). Policías obtuvo buenos datos de audiencia en sus tres años de emisión, con casi un 22\% de share de media y más de 3 millones de espectadores, mientras que Los hombres de Paco obtuvo 19\% de share, superando los 3 
millones de espectadores de media en casi cinco años de emisión. Otras producciones del mismo período se alejan del $20 \%$ de share, tan preciado en la era previa a la actual fragmentación de la audiencia, como Hermanos y detectives (16,9\%), Desaparecida (15,5\%), La chica de ayer (14,8\%), RIS Científica (14,9\%) y Los misterios de Laura (16\%). Génesis (5,6\%), Cuenta atrás $(10,1 \%)$ y UCO $(12,2 \%)$ destacan por presentar audiencias inferiores o que rozan el $10 \%$ de share. A lo largo de dos décadas, las producciones de corte progresista son heterogéneas en cuanto a sus vínculos con cadenas públicas o privadas, mientras que las dos producciones de corte conservador de la segunda década se emiten, en su totalidad, en cadenas privadas.

Atendiendo a la división por décadas, al final del monopolio de TVE, Brigada Central logró cierto éxito. Se emitieron dos temporadas y ocupó los primeros puestos en los rankings de atracción y aceptación de los telespectadores (Anuario de RTVE 1989, 83). Petra Delicado contó con un 16,5\% de share.

\section{Representación de la mujer}

Al observar la evolución de la representación de la mujer en el conjunto de ficciones, se constata un cambio positivo durante los 20 años analizados. Tres producciones policíacas han estado protagonizadas por una mujer policía (Mi Teniente, Petra Delicado y Los misterios de Laura).

Los dos temas clave son la incorporación de la mujer a un ámbito laboral con

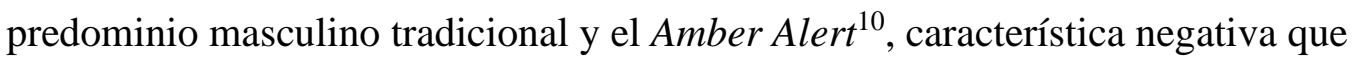
persiste en las dos décadas analizadas; la victimización de las mujeres y la explotación del cuerpo femenino como recurso visual, así como de las agresiones que pueda haber sufrido. Ambos rasgos pueden observarse en Génesis, RIS Científica, Policías (especialmente en la TV-movie Snuff, protagonizada por Vera), aunque las víctimas de estas series no sean solo mujeres. En todos los casos se constata el grado de detalle con que se muestran el ensañamiento y la brutalidad (por ejemplo “Obsesión” y “Ojos sin vida", de Génesis).

Volviendo a la primera década, la primera temporada de Brigada Central ofrece una representación de la mujer marcada por una voluntad moderna y "rompedora", heredera de la denominada "movida madrileña" (estética, costumbres) que finalizó a mediados de 
los años ochenta. Sin embargo, la violencia de género y sexual, lo sórdido de algunos casos y el claro machismo imperante, evidencian el signo de la evolución acontecida del tratamiento de la mujer en la sociedad y en su representación televisiva en España a lo largo de estas últimas décadas. El personaje interpretado por Assumpta Serna (Julia, mujer de Flores) muestra la emancipación de la mujer y las dificultades matrimoniales del protagonista. En la segunda temporada, de estructura independiente, la representación de la mujer es más estereotipada y tradicional, con personajes secundarios caracterizados como femme-fatale o matriarcas de clanes de narcotráfico ("Los herederos", Brigada central, 2.12).

Petra Delicado empieza con un inspector jefe que, falto de recursos, admite la posibilidad de que una mujer se encuentre al mando de un equipo. En un género tradicionalmente protagonizado por hombres, las agentes como Petra Delicado o, diez años más tarde, la protagonista de Los misterios de Laura, llegan a tener tanta o más consideración que sus compañeros, con una representación positiva de la mujer ${ }^{11}$. Fermín (Santiago Segura) es uno de los pocos personajes masculinos subalternos de una inspectora en la ficción policíaca analizada. Petra Delicado critica y denuncia comportamientos machistas, como la prostitución de mujeres migrantes que los proxenetas del caso plantean como forma de regreso al modelo "tradicional"; de mujer sumisa, que la protagonista califica de "aterrador; una forma de esclavitud" ("Dulce compañía”, 1.3). Ya en la segunda década, Laura Lebrel del Bosque (María Pujalte), la inspectora de policía que protagoniza Los misterios de Laura, compagina la profesión con la familia y se guía por su intuición. Tiene una apariencia bondadosa y cándida, maternal, que contrasta con la sagacidad empleada en la resolución de los $\operatorname{casos}^{12}$. En 2007 se había aprobado la Ley de Igualdad del Gobierno Zapatero.

En otras ocasiones, la consideración positiva de la mujer policía se produce gracias al rol de la forense o la agente escrupulosa y culta: Ana Galeano (Irene Montalà) y Claudia Barea (Belén López) en RIS y Lola Casado (Verónica Sánchez) de Génesis; y las forenses de El comisario. Dichos personajes femeninos adquieren rasgos del "joven superdotado", propio de las series estadounidenses (Numb3rs, Mentes criminales, Bones). Los personajes masculinos raramente adoptan dicho perfil: sí lo hacen Lorenzo Montero (Rodrigo Noya), el niño de Hermanos y detectives y Seca (Roger Coma), investigador en la segunda temporada de Génesis. En general, los personajes masculinos se caracterizan por ser hombres de acción, como Lucas (Hugo Silva) en Los hombres de 
Paco; Daniel (Quim Gutiérrez) en Génesis; Rafa (Daniel Guzmán) y Mateo (Toni Sevilla) en Policías, quienes se muestran más preocupados por la acción inmediata que por cumplir la ley a rajatabla (Corso en Cuenta atrás ${ }^{13}$, Charlie y Pope de El comisario). La caracterización de estos personajes va acompañada de cierta promiscuidad en las relaciones amorosas. A propósito de la acción en Policías, Smith describe la serie como "Americanized and action-based", mientras que El comisario es un producto "more Spanish, more close" (Smith 2007, 63), y favorece la "domesticidad" (Smith 2007, 68).

La tipología del género policíaco que puede establecerse según el método de investigación, ya sea analítico (Sherlock Holmes) o de acción (policías de calle) ${ }^{14}$, es aplicable, en cierta medida, a la diferenciación de género (mujeres analíticas; hombres de acción). Las mujeres también protagonizan escenas de acción, si bien de modo ocasional, y en varias ocasiones con sanción negativa por parte de sus compañeros ${ }^{15}$. La incorporación de la mujer al mundo profesional se considera un hecho, sobre todo en las producciones de la segunda década, pero la acción policial que requiere uso de la fuerza y violencia es protagonizada generalmente por hombres. Por ejemplo, en RIS Ricardo Ventura (José Coronado) no tiene inconveniente en "asistir" a Ana Galeano (Irene Montalà) para encontrar la IP de un ordenador, pero es él quien la entrena en la tarea de comunicar a los familiares que un ser querido ha fallecido. La especialista informática suele dar órdenes directas a agentes masculinos del equipo, como Damián Bermejo (Pedro Casablanc), policía veterano. Por si fuera poco, Ana Galeano también suele tomar las riendas en las relaciones personales.

En El comisario, las mujeres prácticamente nunca escapan al predominio de la perspectiva androcéntrica; reciben habitualmente la aprobación o reprobación de los hombres, especialmente si no siguen el modelo establecido, ya sea por su ambición (subinspectora Ríos), su caracterización como femme fatale (Raquel y la amante de Genaro en "Cuatro balas", 8.9), su estética (Edurne en "Revancha", 8.9) o sus valores y capacidades (Geli [Ángeles Chamorro] exhibe su carácter maternal en "Sola en casa", 9.5, la oficial Clara Osma [Paula Echevarría] lo hace con un niño soldado en "Cuatro balas”, 8.9). A menudo, las mujeres en la ficción policíaca española son objeto de tópicos que inciden en la perpetuación de estereotipos machistas. Policías presenta un tratamiento de género más respetuoso: las mujeres toman la iniciativa tanto en el dominio profesional (de acción) ${ }^{16}$ como en el amoroso, y son resolutivas y asertivas. La 
actuación de las mujeres no presenta, en general, diferencias significativas con sus compañeros.

En relación a los estereotipos de género, uno de los agentes de El comisario, Pope (Marcial Álvarez), tiene relaciones sentimentales con una monja y con una prostituta, binomio que constituye la tradicional ejemplificación de la representación estereotipada de las mujeres (Dijkstra 1994; Praz 1986). En Los hombres de Paco, el inspector Gonzalo Montoya (Aitor Luna) recurre a un binomio parecido (diosa/puta) para referirse a la traidora Ruth Montalbán (Nerea Garmendia), de la cual estaba enamorado ("El click", 5.1). Continuando con la segunda década, Hermanos y detectives se decanta por el tono cómico para enfocar el androcentrismo. El lenguaje, políticamente incorrecto, de los agentes y del comisario encuentra su contrapunto en la agente María (Inge Martín), la feminista del equipo, quien da lugar a la comicidad que proviene de dicha contraposición. El punto medio lo ofrecen los protagonistas, Lorenzo, Daniel y su compañero, Mansilla (Javier Cifrián). Se observa una burla explícita del uso del femenino en el lenguaje "políticamente correcto" por el subcomisario Serrano (Álex Angulo) ("El secreto de Roque Peralta", 1.2).

Incluso algunas mujeres de las series analizadas contribuyen a perpetuar este tratamiento de género. En El comisario, Geli critica a una mujer cómplice de un caso de violencia de género, sin referirse al hombre que comete la acción ("Asomarse al abismo", 10.9). A diferencia de la representación de la migración, en El comisario no se observa una evolución positiva en la representación de la mujer, y los comentarios androcéntricos persisten hasta las últimas temporadas. En Los hombres de Paco las mujeres pueden ser personajes fuertes (Adriana Ozores), pero están siempre a la sombra de los hombres. El elemento androcéntrico del personaje de Sara (Michelle Jenner) como reclamo erótico de la serie, se ve complementado por la violencia de género de Mariano (Pepón Nieto), que acosa a su primera mujer, Inés (Olga Rodríguez) durante la primera temporada. Dicha perspectiva se observa también en el contraste entre el protagonista, Paco Miranda (Paco Tous), preocupado por salvaguardar a su hija Sara en lo sentimental, y la rebeldía en las acciones de esta, que se expresa tanto en la vestimenta como en la relación sentimental "prohibida" con el hombre que fue su tío y, sucesivamente, compañero en comisaría, Lucas Fernández. 
La representación positiva de la imagen de la mujer proviene de su tratamiento no diferenciado en actuaciones profesionales y personales (como en Policías) y se trata de una igualdad que se suelen otorgar a sí mismas las propias protagonistas (Petra Delicado, la protagonista de Los misterios de Laura, María en Hermanos y detectives; Leo en Cuenta atrás) en relación a rasgos tales como la independencia, la autonomía, o la iniciativa tanto personal como profesional. Se observa una cierta mejora en relación a la masculinización de los personajes femeninos de las series policíacas, constatada por Galán $(2007,231)$.

Nos referimos a una evolución en la representación de la mujer en cuanto se refiere a valores de superficie, los cuales no operan en profundidad, cuando en la producción se explicitan una serie de valores "progresistas" pero la actuación de los personajes es, sin embargo, "tradicional". Es el caso de El comisario y, en ocasiones, de Cuenta atrás. En El comisario se ejemplifica como sigue: mientras que desde los inicios se plantea que el trato en comisaría a las mujeres que han sufrido una violación debería mejorar (“Ojo por ojo", 1.6) ${ }^{17}$, y los agentes no toleran los insultos a una mujer negra ${ }^{18}$ (narrativa de superficie); el cuerpo de la mujer recibe miradas constantes por parte de los agentes (cosificación) y, aunque los agentes son censurados por sus comentarios, estos son con frecuencia políticamente incorrectos (valores profundos), especialmente por parte de Charlie.

Se observan rasgos de mejora de la representación de la mujer en las ficciones analizadas, que se acompañan de cambios sociales como la aprobación de la Ley de igualdad en 2007 por el PSOE, pero es preeminente la mirada androcéntrica, especialmente en las producciones más exitosas (cadenas privadas), y perdura el Amber Alert de modo generalizado.

\section{Marginalidad}

El recorrido por el policíaco español de las dos décadas analizadas revela un tratamiento muy distinto de la marginalidad. Aquella parte de la sociedad excluida del funcionamiento cotidiano de la misma, por motivos laborales y pecuniarios, nos permite inferir en qué posición (progresismo/ conservadurismo) está situada la producción de la serie. Por ejemplo, en la primera temporada de Brigada Central, serie emblemática de la 
primera década analizada, este indicador puede considerarse parte de una función divulgativa, que sirve para dar a conocer a los espectadores una parte de la sociedad del modo más crudo posible (etnia gitana, prostitución de menores, drogadicción, bajos fondos), en consonancia con la estética cinéma verité propia de Canción triste de Hill Street (Zunzunegui y Zubillaga 1998; González de Garay 2012b, 5). La segunda temporada se presenta como una buddy movie desde el primer episodio ("Érase una vez dos polis", Brigada central, 2.1), con el personaje de Stan (Jose Manuel Cervino) acompañando a Flores, y se centra más en el narcotráfico.

La distancia entre los agentes y la sociedad marginada se va difuminando en las producciones audiovisuales del período analizado. Se mantiene el retrato de la marginalidad y la delincuencia, pero el objetivo es denunciar la permeabilidad y contigüidad de ambos fenómenos con las clases medias a las que va dirigida la producción. El personaje de Champorion (José María Tasso) representa la marginalidad y se convierte en un secundario recurrente en Petra Delicado (integración en la trama). Y, dejando a un lado la inclusión en la sociedad de la etnia gitana que supone la aparición del personaje de Flores (Imanol Arias), no hay tanta diferencia de clases sociales entre los agentes y los delincuentes/víctimas en producciones de la segunda década analizada, en Policías, El comisario o Los hombres de Paco como la que había en la serie de Pedro Masó. Es recurrente la presencia (integración) de un agente que proviene de los bajos fondos y se ha hecho policía: Pope en El comisario; Rafa (Daniel Guzmán) en Policías. En El comisario los agentes muestran su rechazo a unos vecinos ricos que criminalizan a unos indigentes y llegan a matar a uno de ellos ("Sin pruebas", 2.4). Policías nos muestra cómo puede acabar un expolicía, denunciado por mala praxis, al borde de la marginalidad (Cipriano en "Odio y amo", 6.13).

El comisario apuesta por la función divulgativa, mostrando al espectador "aquello que no se debe hacer" y los peligros de la delincuencia y la marginalidad, que pueden estar más próximos a su clase social de lo que sería deseable, con casos que pueden afectar al target de la serie: una audiencia de clase media (neonazis, drogas, migración, trabajo, criminalidad, seguridad, violencia de género). Tomarse la justicia por la propia mano tiene también una sanción negativa en El comisario (y en RIS Científica con el personaje de Cuevas [Juan Fernández]). El reclamo por parte de la sociedad de que se haga justicia mediante la acción policial es recurrente en las dos series (también en Policías) y recibe una sanción positiva, contribuyendo así a reforzar la función de las 
fuerzas y cuerpos policiales como institución social. En el primer episodio de $E l$ comisario, observamos cómo el agente Pope previene al hijo de un compañero acerca de los peligros de las drogas.

En El comisario, las vivencias personales de los agentes complementan la transmisión de valores, al mismo tiempo que hacen hincapié en aspectos de la vida cotidiana y refuerzan el punto de vista transmitido mediante los casos policiales. La perspectiva habitualmente androcéntrica, dirigida a un espectador medio cuyas preocupaciones se asumen similares a las de los agentes y los casos policiales (con los temas ya mencionados), se complementa con cuestiones de orden doméstico, como la escuela, la familia, el trabajo, la vivienda, problemas con la bebida, etc.

\section{Migración}

La representación de los migrantes en la ficción española va evolucionando con el tiempo en la mayoría de producciones (entre ellas El comisario). Cabe recordar que en la segunda década del período analizado se produce la llegada masiva de migrantes a España (a partir del año 2000), que desciende a causa de la crisis económica (a partir del 2012).

En los últimos años se constata un incremento de personajes extranjeros/inmigrantes que encarnan las configuraciones moderadas de segregación, asimilación e integración, consecuente con la progresiva disminución de personajes representativos de las configuraciones extremas de expulsión, admisión e integración de sus respectivos ámbitos de relación entre la identidad y la alteridad. (Lacalle 2008, 125)

También es aplicable la diferencia entre los valores de superficie, con afirmaciones como "No todos los sudamericanos estamos metidos en pandillas ni sabemos bailar salsa"; y los valores profundos -se muestra un retrato estereotipado de la comunidad mediante los fragmentos de videoclip (Tous-Rovirosa 2008, 104) en el mismo episodio, con música de reguetón, imágenes nocturnas, peluquerías y otros comercios de migrantes, callejuelas, bandas, hogueras, y un tono rojizo propio de las analepsis, a menudo asociadas a la violencia. El conjunto de tópicos asociado a una etnia determinada aparece en todas las producciones que contienen ambientaciones 
geográficas diferenciadas (Cuenta atrás, Soy el solitario). Tanto en Cuenta atrás ${ }^{19}$ como en El comisario dicha vinculación va asociada explícitamente a la violencia (tribus urbanas, mafias).

Los agentes de El comisario suelen juzgar de manera negativa a los ciudadanos $\operatorname{racistas}^{20}$. En la novena temporada, el ecuatoriano que protagoniza el caso contrapone a los migrantes trabajadores con los "ninis" españoles ("Revancha", 9.11). El retrato de los migrantes va evolucionando positivamente en las últimas temporadas, cuando se incluye en las tramas la representación de migrantes trabajadores, integrados en la sociedad, y se forja una representación positiva, también, de su tiempo de ocio (temporadas $9^{\mathrm{a}}-12^{\mathrm{a}}$, años 2005-2009).

En una miniserie de 2008 como Soy el solitario, el policía mexicano bromea con la profesionalidad de sus colegas españoles, que debería ser "superior", acorde con los estereotipos y prejuicios respecto a la migración. Cuando el agente español, Pereira, le dice: "Necesitamos saber cómo se mueve [el atracador]; el mexicano responde: "Qué raro. Nosotros preferimos huellas, ADN, etc." (Soy el solitario).

En Petra Delicado, serie de la primera década, a medida que avanza la serie, los comentarios referentes a los migrantes mejoran (si bien son tópicos desde el episodio piloto), al ir incorporando la "particular forma de ver el mundo" de Petra, que hace preguntas tales como si Ifigenia, la criada colombiana, está dada de alta en la seguridad social ("Dulce compañía", 1.3.), y defiende a un chico de color de unos neonazis en "Tu muerte está cerca" (1.6).

La Ley de Extranjería y sus modificaciones dan cuenta de que se trata de un tema de preocupación social en España. Se observa en la evolución de las ficciones analizadas que su tratamiento es cada vez más positivo.

\section{Homosexualidad}

Resultan sorprendentes, aunque comprensibles desde un punto de vista histórico, las bromas y tópicos sobre homosexuales y migrantes en Petra Delicado (1999); e incluso sobre la mujer ${ }^{21}$, en una serie caracterizada por el progresismo ${ }^{22}$ y la defensa de mujeres 
emancipadas e independientes como la protagonista ${ }^{23}$, lo que se consideraba extremadamente "moderno" a finales de los 90.

En relación con la homosexualidad, algunos personajes de El comisario son políticamente incorrectos ${ }^{24}$. En 2005, en la penúltima temporada, el término despectivo para referirse a los homosexuales seguía utilizándose en El $_{\text {comisario }}{ }^{25}$. Dichos términos se usan en La chica de ayer para mostrar los cambios y evolución habida en 32 años de diferencia (1977-2009) ${ }^{26}$, incorporando cierta función divulgativa por parte de Samuel Santos frente a sus compañeros, al diferenciar entre "agresión homófoba" y “crimen pasional" 27 . El matrimonio entre personas del mismo sexo es legal a partir de 2005, cuando finaliza El comisario y 4 años antes del inicio de La chica de ayer.

Los hombres de Paco presentará una relación sentimental entre Silvia Castro (Marian Aguilera) y Pepa Miranda (Laura Sánchez) a partir de "La noche del comisario" (4.5) (emitido en 2008, tres años después de la aprobación del matrimonio homosexual en España). Ésta evidencia una evolución positiva en relación al tratamiento de la homosexualidad, normalizada en la ficción, sin obviar los conflictos y dificultades derivados de dicho proceso, que culmina con la (difícil y costosa) aceptación por parte del padre de Silvia, el comisario Lorenzo Castro (Juan Diego), y la boda. Tal como ha estudiado González de Garay (2012a), se observa una representación “integrada" del lesbianismo en la ficción española, aunque la representación a lo largo de la historia televisiva española hasta 2011 ha sido también "oculta, marginalizadora, reivindicativa". En este caso, destaca una normalización de la relación homosexual sin mencionar en ningún momento la subcultura LGTB (González de Garay 2012a, 349).

\section{La imagen de los cuerpos policiales}

A principios de los años 90, la Guardia Civil llegó a parar el rodaje de la serie Brigada central, que se reanudó con la presencia de un inspector con derecho a corregir y vetar las grabaciones (Madrid, 2010). Pese a ese principio conflictivo, la serie buscaba legitimar el rol del policía tras la dictadura, a la vez que se mostraba escéptica y crítica con el sistema, como afirma González de Garay (2012b, 8) y como observamos también en Petra Delicado. Son varias las producciones en las que la Guardia Civil y/o la Policía Nacional son caracterizadas de manera positiva, a excepción de las primeras 
temporadas de Los hombres de Paco. La caracterización depende también del enfoque “ideológico" de la producción, más positiva en las producciones de TVE Desaparecida y $U C O$ respecto a la Guardia Civil, y la de Antena3 Soy el solitario ${ }^{28}$, mientras en Génesis, de Cuatro, se la sigue mostrando como un cuerpo hermético e inamovible ${ }^{29}$. En la miniserie Soy el solitario se contrapone la figura de Alfredo (Ramón Barea), clásico veterano del cuerpo, con los agentes jóvenes que regeneran la Guardia $\mathrm{Civil}^{30}$. Todos ellos comandados por Herrera (Emilio Gutiérrez Caba). Soy el solitario llega a incorporar en una trama una disputa entre cuerpos policiales, ya que la Policía Nacional también considera un caso como propio de su jurisdicción. Un atributo que suele caracterizar a los agentes es el sacrificio personal por un trabajo no siempre bien remunerado (Fermín en "Dulce compañía”, Petra Delicado, 1.3.; Flores en "Los herederos", Brigada Central, 2.12).

Tal como afirma Colmeiro (2015, 16-17), el género policial se desarrolla paralelamente a cambios sociales y políticos (urbanización y democratización) acontecidos en las últimas décadas en España y gran parte de Latinoamérica. Consideramos que dicha interpretación del género literario es plenamente aplicable a la producción televisiva. Con la transición, el género literario pasa de ser popular a un thriller urbano híbrido sin las "limitaciones del realismo social" (Colmeiro 2015, 22). "La ruptura cultural con el franquismo, el olvido del pasado histórico, la corrupción de las élites económicas y los cuerpos policiales, y sus conexiones con la corrupción del sistema legal, serán temas recurrentes en la nueva novela negra española" (Colmeiro $2015,22)$. Se trata de un análisis plenamente aplicable a la primera década analizada (Pepe Carvalho, Petra Delicado, Hermanos y detectives, Pájaro en una tormenta y Brigada Central). Son relevantes y pertinentes también las aportaciones de Piper (2015), que ve en el detective un rol privilegiado como voz disidente de la sociedad, y de Turnbull, que lo define como "héroe" (Turnbull 2014, 97-124). Inferimos por tanto que el género policíaco permite la reinterpretación del pasado reciente, a la vez que introduce atribuciones o presunciones de heroicidad en los protagonistas, ya sean conservadores (Valverde y su equipo en El comisario) o progresistas (Ferré en Policías, Petra Delicado, Laura en los Misterios de Laura). 


\section{Conclusiones}

Se ratifica la hipótesis: las cadenas privadas presentan valores más conservadores que la cadena pública en sus emisiones de los títulos de género policíaco, por lo que se produce una involución en el tiempo del tratamiento de dichos valores. En el periodo analizado, el enfoque de la mujer y la marginalidad se presentan cada vez más bajo una mirada conservadora, mientras que el tratamiento de los migrantes y de la homosexualidad mejora, a causa de la preocupación social por dichas cuestiones. Aunque política y socialmente existe preocupación por la mayoría de estas cuestiones, como lo demuestran tanto la Ley de Igualdad de 2007 como la aprobación del matrimonio homosexual en 2005 y las sucesivas reformas de la Ley de Extranjería (2000, 2003 y 2009), sobre todo se observa una mejora en la representación de estos dos últimos temas.

En cuanto a los valores transmitidos por las series analizadas, se observa una importante diferenciación entre aquellas de corte más moralista y conservador, pertenecientes a la segunda década analizada (El comisario, Los hombres de Paco), y las más progresistas, ya sean de la primera década analizada (Petra Delicado, Pepe Carvalho, Brigada Central), o de la segunda (Génesis, Los misterios de Laura, Desaparecida, Policías. En el corazón de la calle, Cuenta atrás). En series de la primera década, los valores de superficie pueden ser conservadores, mientras que aquellos que aparecen denotados en la estructura, en las capas interpretativas de mayor profundidad o complejidad, son progresistas, a la inversa de lo que sucede en las mencionadas series posteriores, líderes de audiencia.

Es en las series más longevas y de más audiencia (emblemáticas de las respectivas cadenas) concretamente Los hombres de Paco y El comisario, donde persiste una perspectiva androcéntrica y se hace eco de valores más conservadores. A menudo las mujeres en la ficción policíaca española son objeto de una mirada que abunda en los tópicos e incide en la perpetuación de estereotipos machistas. A diferencia de la representación de la migración, en El comisario no se observa una evolución positiva en el tratamiento de la mujer, y los comentarios androcéntricos persisten hasta las últimas temporadas.

Se observa cierta progresión en el tratamiento de temas como el machismo, la migración, la homosexualidad y los estereotipos de género y racistas; pero, salvo 
excepciones, esta se produce más en superficie que en profundidad. En relación a la evolución y uso de estereotipos, cabe destacar la diferenciación entre series de corte conservador, como El comisario, y series más progresistas, como Génesis, en las que los personajes actúan con mucha cautela para no caer en tópicos ni estereotipos.

En las dos décadas estudiadas, las producciones de corte progresista se muestran heterogéneas en lo que respecta a la distinción entre cadenas públicas o privadas, mientras que las producciones de corte conservador de la segunda década se emiten exclusivamente en las cadenas privadas. Asimismo, producciones emblemáticas de corte progresista como Brigada Central, Los misterios de Laura y Desaparecida se emitieron en TVE1 durante legislaturas del partido socialista.

Las vicisitudes de RTVE (que tuvo que reinventarse) con el auge de las privadas no suponen una desaparición de los agentes políticos (poder ejecutivo) como condicionantes de la actividad de radiotelevisión española (Bustamante 2013). El auge de las privadas coincide con la medición de audiencias. Todas las televisiones incorporan nuevos sistemas que tratan de privilegiar aquellos programas capaces de llegar al mayor público posible (Palacio 2001, 167). La reacción a la competencia entre cadenas varía a partir de 2004, cuando Zapatero llega al poder y se encuentra con una televisión pública que, entre otros problemas, tiene poca audiencia y un exceso de programas "basura” (Smith 2006). En los 20 años de televisión (género policíaco) analizados, observamos algunas tendencias que nos permiten coincidir con la afirmación de Smith: "TV, even at its most trivial, thus runs parallel to politics" (Smith 2006, 157).

A modo de síntesis, el género policíaco empieza en manos de RTVE, justo después de que su monopolio haya finalizado. Durante las legislaturas socialistas de Felipe González (1989-1996), en 1992, se produce el auge de telerrealidad, en el que compiten cadenas públicas y privadas, con una ausencia de 6 años del género en las parrillas, entre 1993 y 1999 (finalizando con el auge del PP en 1996). Con el cambio de milenio, y ya durante los mandatos de Aznar (1996-2004), llegan El Comisario, Policías y, posteriormente, con las legislaturas de Zapatero (2004-2011), Los hombres de Paco (2005). Estas son las producciones de mayor audiencia, duración, y en el primer y último casos, valores más conservadores. Es entonces, coincidiendo con una mayor madurez del sistema televisivo español y la llegada al poder del PSOE, cuando se 
produce un auge de la ficción policiaca, de cuyo polimorfismo destacamos las producciones en RTVE de temática social y corte progresista, que muestran un tratamiento positivo de la mujer, como Desaparecida o Los misterios de Laura, recuperando así tendencias propias de ficciones anteriores (la Ley de Igualdad se aprueba en 2007). En ese mismo quinquenio, una de las cadenas privadas, Antena 3, propone una amable relectura de la Transición con La chica de Ayer (Antena 3, 2009) (Cascajosa 2012), en lo que posteriormente se ha podido observar como tendencia recurrente con producciones como El tiempo entre costuras (Antena 3, 2013-2014) y Velvet (Antena 3, 2014-2016). La representación de la mujer mejora, probablemente en parte gracias a la aprobación de la Ley de Igualdad. Pero, como ocurre con otras figuras y temáticas, como la migración o el matrimonio homosexual, en líneas generales la mejora se produce es-solo en la superficie, pues no llega a los valores axiológicos de las capas profundas.

\section{Agradecimientos}

La autora de este artículo se muestra agradecida a los revisores anónimos por su valiosa tarea. Este artículo ha sido elaborado en el marco del proyecto Historia de la programación y programas de ficción televisiva en España (cadenas de ámbito estatal): De la desregulación al apagón analógico, 1990-2010 (CSO2015-66260-C4-4-P), financiado por el Ministerio de Economía y Competitividad. Los datos de la producción de ficción española entre 2008 y 2010 proceden de los respectivos informes elaborados por el equipo español de Obitel (Observatorio Iberoamericano de Ficción Televisiva).

\section{Nota biográfica}

Anna Tous-Rovirosa es profesora agregada de la Facultad de Ciencias de la Comunicación (Universidad Autónoma de Barcelona). Como investigadora especializada en narrativa audiovisual, análisis de la TV e interactividad de la ficción, ha publicado varios artículos y los libros La política en las series de televisión (ed.) (UOC, 2015), Mites en sèrie: Els temes clau de la TV (Trípodos, 2013), así como La era del drama en televisión (UOC, 2010). Ha sido profesora visitante en la Universidad del 
Rühr University (Bochum, Alemania) y de la Universidad Federal de Bahia (UFBA),

Brasil. Obtuvo el II Premio en Investigación sobre Comunicación del Consell

Audiovisual de Catalunya (CAC) y es miembro de los reconocidos grupos Ofent y

Localcom (UAB).Email: Anna.Tous@uab.cat

$\underline{\text { Tabla de los } 36 \text { títulos policíacos españoles (1990-2010) }}$

\begin{tabular}{|c|c|c|c|}
\hline Título & Cadena & Años & Formato \\
\hline Eurocops & $\mathrm{La} 2$ & $1988-1992$ & Serie \\
\hline Brigada central & TVE1 & 1989-1992 & Serie \\
\hline Pájaro en una tormenta & TVE1 & 1990 & Serie \\
\hline Alta tensión & La 2 & 1993 & Serie \\
\hline Petra Delicado & Tele 5 & 1999 & Serie \\
\hline Camino de Santiago & Antena 3 & 1999 & Miniserie \\
\hline Pepe Carvalho & Tele5 & $1999-2000$ & Serie \\
\hline El comisario & Tele5 & 1999-2009 & Serie \\
\hline Antivicio & Antena 3 & 2000 & Serie \\
\hline $\begin{array}{l}\text { Policías: En el corazón de la } \\
\text { calle }\end{array}$ & Antena 3 & $2000-2003$ & Serie \\
\hline Mateo y Rafa & Antena 3 & 2000 & TV-movie \\
\hline Ferrer y Ruso & Antena 3 & 2000 & TV-movie \\
\hline Robles Investigador privado & TVE1 & $2000-2001$ & Serie \\
\hline Lucía y Carlos & Antena 3 & 2001 & TV-movie \\
\hline Mi teniente & TVE1 & 2001 & Serie \\
\hline Snuff & Antena 3 & 2003 & TV-movie \\
\hline Lobos & Antena 3 & 2005 & Serie \\
\hline Los hombres de Paco & Antena 3 & $2005-2010$ & Serie \\
\hline
\end{tabular}




\begin{tabular}{|c|c|c|c|}
\hline $\begin{array}{lll}\text { Suárez y } & \text { Mariscal caso } \\
\text { cerrado } & & \\
\end{array}$ & Cuatro & 2005 & Serial \\
\hline RIS Científica & Tele 5 & 2007 & Serie \\
\hline $\begin{array}{l}\text { Génesis: En la mente del } \\
\text { asesino }\end{array}$ & Cuatro & 2006-2007 & Serie \\
\hline Cuenta atrás & Cuatro & $2007-2008$ & Serie \\
\hline Desaparecida & TVE1 & $2007-2008$ & Serie \\
\hline Hermanos y detectives & Tele 5 & $2007-2009$ & Serie \\
\hline Soy el solitario & Antena 3 & 2008 & Miniserie \\
\hline Fago & TVE1 & 2008 & Miniserie \\
\hline 48 horas & Antena 3 & 2008 & Miniserie \\
\hline Cazadores de hombres & Antena 3 & 2008 & Serie \\
\hline Guante blanco & TVE1 & 2008 & Serie \\
\hline El caso Wanninkhof & TVE1 & 2008 & Miniserie \\
\hline$U C O$ & TVE1 & $2008-2009$ & Serie \\
\hline Una bala para el Rey & Antena 3 & 2009 & Miniserie \\
\hline El Bloke coslada cero & TVE1 & 2009 & Miniserie \\
\hline La chica de ayer & Antena 3 & 2009 & Serie \\
\hline $\begin{array}{l}\text { El crimen de los marqueses } \\
\text { de Urquijo }\end{array}$ & TVE1 & 2009 & TV-movie \\
\hline Los misterios de Laura & TVE1 & 2009-2014 & Serie \\
\hline
\end{tabular}

Fuente: Elaboración propia

Ficha de análisis

\begin{tabular}{|l|l|}
\hline Migración-Integración & 1. Trabajadores \\
& 2. Solidarios \\
& 3. Familiares \\
& 4. Religiosos \\
& 5. Con derechos sociales \\
& 6. Sanción negativa al racismo \\
& 7. Origen \\
\hline
\end{tabular}




\begin{tabular}{|c|c|}
\hline & $\begin{array}{l}\text { 7.1. Latinos } \\
\text { 7.2.Afroamericanos/ subsaharianos } \\
\text { 7.3. Países del Este } \\
\text { 7.4. Etnia gitana } \\
\text { 7.5. Marroquíes } \\
\text { 8. Ocio/ diversión } \\
\text { 9. Contribución económica sociedad } \\
\end{array}$ \\
\hline Migración-Racismo & $\begin{array}{l}\text { 1. violencia y delincuencia } \\
\text { 2. violencia de género } \\
\text { 3. bandas y tribus urbanas } \\
\text { 4. mafias } \\
\text { 5. pobreza (falta de recursos) } \\
\text { 6. inmigración irregular o ilegal } \\
\text { 7. proxenetas, prostitución } \\
\text { 8. narcotraficantes, enfermos } \\
\text { 9. rechazo (insultos) } \\
\text { 10. rechazo (violencia) } \\
\text { 11. víctima (menor) }\end{array}$ \\
\hline Representación de la mujer (positivo) & $\begin{array}{l}\text { 1. independencia, emancipación, autonomía } \\
\text { 2. valentía, dureza } \\
\text { 3. compaginación de vida laboral y familiar } \\
\text { 4. instinto maternal en el ámbito laboral } \\
\text { 5. ambición } \\
\text { 6. minuciosidad } \\
\text { 7. culta } \\
\text { 8. profesionalidad e iniciativa profesional } \\
\text { 9. iniciativa personal } \\
\text { 10. resolución, asertividad } \\
\text { 11. emotivas }\end{array}$ \\
\hline Representación de la mujer (negativo) & $\begin{array}{l}\text { 1. androcentrismo. } \\
\text { 2. Bajo la protección masculina } \\
\text { 3. cosificación de la mujer } \\
\text { 4. violencia de género. Agresiones a niñas } \\
\text { 5. violencia de género. Agresiones a mujeres } \\
\text { 6. Acoso masculino } \\
\text { 7. modelo "tradicional", mujer sumisa } \\
\text { 8. femme fatale/ prostituta } \\
\text { 9. ausencia de acción policial } \\
\text { 10. frías y calculadoras, sin escrúpulos } \\
\text { 11. prostitución }\end{array}$ \\
\hline Homosexualidad (positivo) & $\begin{array}{l}\text { 1. Aceptación de la homosexualidad } \\
2 \text {. Normalización (conflictos y dificultades } \\
\text { derivadas) }\end{array}$ \\
\hline Homosexualidad (negativo) & $\begin{array}{l}\text { 1. insultos } \\
\text { 2. aceptación sólo del modelo } \\
\text { heterosexual/heteropatriarcal } \\
\text { 3. lenguaje políticamente incorrecto, despectivo }\end{array}$ \\
\hline Marginalidad (positivo) & $\begin{array}{l}\text { 1. integración en la sociedad } \\
\text { 2. Integración en la trama } \\
\text { 3. Integración como policía } \\
\text { 4. sanción negativa de equiparar con drogadicción } \\
\text { y delincuencia }\end{array}$ \\
\hline Marginalidad (negativo) & $\begin{array}{l}\text { 1. delincuencia (criminalización) } \\
\text { 2. rechazo (insultos) } \\
\text { 3. rechazo (violencia) } \\
\text { 4. etnias } \\
\text { 5. prostitución de menores } \\
\text { 6. drogadicción } \\
\text { 7. bajos fondos }\end{array}$ \\
\hline Cuerpos policiales (positivo) & 1. preocupación por las personas \\
\hline
\end{tabular}




\begin{tabular}{|c|c|}
\hline & $\begin{array}{l}\text { 2. responsabilidad } \\
\text { 3. Modernidad. Incorporación de nuevas } \\
\text { tecnologías } \\
\text { 4. Modernidad. Agentes jóvenes } \\
\text { 5. trabajo sacrificado (sueldos bajos) } \\
\text { 6. cuestionar statu quo vigente }\end{array}$ \\
\hline Cuerpos policiales (negativo) & $\begin{array}{l}\text { 1. Hermética } \\
\text { 2. Inamovible } \\
\text { 3. irresponsable } \\
\text { 4. anticuada } \\
\text { 5. corrupción } \\
\text { 6. violencia injustificada, abuso } \\
\text { 7. justicia por su mano }\end{array}$ \\
\hline Relevancia del personaje & $\begin{array}{l}\text { 1.Personaje principal } \\
\text { 2.Personaje secundario } \\
\text { 3.Personaje de reparto }\end{array}$ \\
\hline Relevancia de la trama & $\begin{array}{l}\text { 1. Trama principal } \\
\text { 2. Trama secundaria } \\
\text { 3. Trama puntual o anecdótica }\end{array}$ \\
\hline
\end{tabular}

Fuente: Elaboración propia

\section{Referencias}

Altheide, David L. 2000. “Tracking Discourse and Qualitative Document Analysis.” Poetics 27: 287-299.

Anuario de RTVE.1989. Madrid: Servicio de Publicaciones RTVE.

Aran, Sue, Pilar Medina, y Miquel Rodrigo. 2011. "Management of Emotions in American Fiction Series: When Being (and Feeling) Woman Sells." International Journal of Arts and Technology 4 (1): 6-18.

http://dx.doi.org/10.1504/IJART.2011.037766

Benshoff, Harry, y Sean Griffin. 2005. Queer Images: A History of Gay and Lesbian

Film in America. Lanham, MI: Rowman \& Littlefield Publishers.

Bustamante, Enrique. 2013. Historia de la radio y la televisión en España. Barcelona: Gedisa.

Cascajosa, Concepción. 2012. "La chica de ayer: Memoria y desmemoria televisivas de la Transición en España.” Journal of Spanish Cultural Studies 13 (3): 260-275.

Colmeiro, José. 2014. "Novela policíaca, novela política.” Lectora 21: 15-29. 
Cooke, Les. 2001. “The Police Series.” En The Television Genre Book, editado por Glen Creeber, 19-23. Londres: British Film Institute.

Creeber, Glen, ed. 2001. The Television Genre Book. Londres: British Film Institute.

Diego, Patricia. 2010. La ficción en la pequeña pantalla: Cincuenta años de series en España. Pamplona: Eunsa.

Dijkstra, Bram. 1994. Ídolos de la perversidad. Barcelona: Debate.

Fouts, Gregory, y Kimberly Burggraf. 1999. “Television Situation Comedies: Female Body Images and Verbal Reinforcements." Sex Roles 40: 473-481. doi:10.1023/A:1018875711082

Galán Fajardo, Elena. 2006. "La representación de los inmigrantes en la ficción televisiva en España: Propuesta para un análisis de contenido.” El Comisario y Hospital Central: Revista Latina de Comunicación Social 61. http://www.revistalatinacs.org/200608galan.pdf

Galán Fajardo, Elena. 2007. "Construcción de género y ficción televisiva en España.” Comunicar: Revista Científica Iberoamericana de Comunicación y Educación 28: $229-236$.

García Muñoz, Nuria, Madalena Fedele, y Xiana Gómez-Díaz. 2012. “The Occupational Roles of Television Fiction Characters in Spain: Distinguishing Traits." Comunicación y Sociedad 25 (1): 349-366.

GECA. El anuario de la televisión en España. Madrid, 2000, 2001, 2002, 2003, 2004, 2005, 2006.

Gerbner, George, Larry Gross, Marylin Jackson-Beeck, Suzanne Jeffries-Fox, y Nancy Signorielli. 1978. "Cultural Indicators: Violence Profile No. 9.” Journal of Communication 28 (3). http://DOI 10.1111/j.1460-2466.1978.tb01646.x 
González de Garay, Beatriz. 2012a. "La representación de la homosexualidad femenina en Hospital Central en el período 2004-2006.” Tesis doctoral, Universidad Complutense de Madrid.

González de Garay, Beatriz. 2012b. "Hacia una contextualización histórico-cultural de Brigada central (TVE1: 1989).” Área abierta 12 (2): 1-17.

Gordillo, Inma, y Virginia Guarinos. 2010. Todos los cuerpos: El cuerpo en televisión como obsesión hípermoderna. Córdoba, Argentina: Babel Ed.

Lacalle, Charo. 2008. El discurso televisivo sobre la inmigración: Ficción y construcción de identidad. Barcelona: Omega.

Lacalle, Charo, y Beatriz Gómez. 2016. “La representación de las mujeres trabajadoras en la ficción televisiva española." Comunicar: Revista Científica Iberoamericana de Comunicación y Educación 47 (24): 59-67.

Madrid, Juan. 2010. Brigada central. Barcelona: Ediciones B.

Medina, Pilar; Rodrigo, Miquel. 2009. “Análisis de la estructura narrativa del discurso amoroso en la ficción audiovisual: Estudio de caso: "Los Serrano" y "Porca Misèria." Zer: Revista de Estudios de Comunicación 12: 83-101.

Melero, Alejandro. 2012. “Gays y lesbianas en la ficción televisiva española de la democracia." En De Anatomía de Grey a The Wire. La realidad de la ficción televisiva, editado por Iñaki Martínez y Carmelo Moreno, 129-146. Madrid: Los Libros de la Catarata.

Praz, Mario. [1986] 1999. La carne, la muerte y el diablo en la literatura romántica. Barcelona: El Acantilado.

Piper, Helen. 2015. The TV Detective: Voices of Dissent in Contemporary Television. Londres: IB Tauris. 
Romero Santos, Rubén. 2015. "Mucha policía, mucha diversión: La ficción criminal en la televisión española." En Ficcionando en el siglo XXI: La ficción televisiva en España, editado por Belén Puebla et al., 261-276. Madrid: Icono 14.

Rueda Laffond, José Carlos, y Ma del Mar Chicharro Merayo. 2006. La televisión en España (1956-2006): Política, consumo y cultura televisiva. Madrid: Editorial Fragua.

Rueda Laffond, José Carlos, y Carlota Coronado Ruiz. 2016. "Historical Science Fiction: From Televisión Memory to Transmedia Memory in El Ministerio del Tiempo.” Journal of Spanish Cultural Studies 17: 87-101. https://doi.org/10.1080/14636204.2015.1135601

Ruiz Collantes, Xavier, Joan Ferrés, Matilde Obradors, Eva Pujadas, y Oliver Pérez. 2006. “La imagen pública de la inmigración en las series de televisión.” Quaderns del CAC 23-24: 107-132.

Russo, Vito. 1981. The Celluloid Closet: Homosexuality in the Movies. Nueva York: Harper \& Row.

Sanmartín, Israel. 2007. Entre dos siglos: Globalización y pensamiento único. Madrid: Akal.

Smith, Paul Julian. 2006. Television in Spain: From Franco to Almodóvar. Woodbridge, UK: Tamesis.

Smith, Paul Julian. 2007. "Crime Scenes: Police Drama on Spanish Television.” Journal of Spanish Cultural Studies 8 (1): 55-69.

Torrado Pelaéz, Daniel. 2017. "La falacia dramática en la ficción televisiva nacional y su relación con los índices de audiencia. Análisis del medio televisivo en términos 
de mercadotecnia. El caso de Los hombres de Paco." Tesis doctoral, Universidad de Sevilla.

Torras, Meri. 2006. "Cuerpos en serie: Roles, géneros y sexualidades en CSI.” Mujeres en serie. Discursos de género en la ficción televisiva del nuevo milenio, Número especial Revista Género y Comunicación, Madrid: 79-101.

Torres, Sasha. 1996. "The Caped Crusader of Camp: Pop, Camp and the Television Series of Batman.” En Pop Out: Queer Warhol, editado por Jennifer Doyle, Jonathan Flatley, y José Esteban Muñoz, 238-255. Durham, NC: Duke University Press:

Tous-Rovirosa, Anna. 2008. “El text audiovisual: Anàlisi des d'una perspectiva mediològica.” Tesis doctoral, Universidad Autónoma de Barcelona.

Tous-Rovirosa, Anna, Koldo Meso-Ayerdi, y Nuria Simelio-Solà. 2013. "The Representation of Women's Roles in Television Series in Spain: Analysis of the Basque and Catalan Cases." Comunicación y Sociedad 26 (3): 67-97.

Tous-Rovirosa, Anna, y Sue Aran-Ramspott. 2017. "Mujeres en las series políticas contemporáneas. ¿Una geografía común de su presencia en la esfera pública?” El Profesional de la Información 26 (4): 684-694.

Turnbull, Sue. 2014. The TV Crime Drama. Edinburgh: Edinburgh University Press. Vilches, Lorenzo, Rosa Berciano, y Charo Lacalle, et al. 2000. "Informe Eurofiction 1999: Menos familia y más policía.” Zer: Revista de Estudios de Comunicación 9. Zunzunegui, Santos, y Juan Zubillaga. 1988. “Tengan mucho cuidado ahí dentro: Hill Street Blues o los variados matices del gris." Vol. 2 de Documentos de trabajo del Centro de Semiótica y Teoría del Espectáculo. Valencia: Fundación Instituto Shakespeare / Instituto de Cine y RTV. 


\section{Notas}

${ }^{1}$ Seis episodios, dos en cada país excepto Italia, con solo 1.

2 (TVE, Antenne 2 y RTV Luxembourgeise)

${ }^{3}$ Los datos de audiencia corresponden al share total de las producciones analizadas.

${ }^{4}$ http://www.manuelriossanmartin.com/miniseries/el-solitario. Dos capítulos conforman la miniserie: "El hombre sin huellas" y "Operación Silvia".

${ }^{5}$ Las dos primeras temporadas contaban con seis episodios cada una, y se emitieron respectivamente en 1985 y 1991. Los episodios de La huella del crimen 2 fueron: "El caso de Carmen Broto", "El crimen de Perpignan", "El crimen de Don Benito", "El crimen de las estanqueras de Sevilla", "El crimen del expreso de Andalucía" y "Amantes". "El crimen de los marqueses de Urquijo" es el primer episodio de la tercera temporada, seguida por "El secuestro de Anabel" y "El asesino dentro del círculo".

${ }^{6}$ Especialmente al inicio de la investigación, frente al miedo a declarar de los jóvenes implicados en el caso, Sierra y Andrún les insisten en que es preferible haber mantenido relaciones sexuales que ser sospechoso de asesinato ("Día 4", 1.2 y "Día 11", 1.3, Desaparecida).

${ }^{7}$ Pepe Carvalho, de 1986, presenta un tratamiento de la homosexualidad bastante progresista. En la de 1999 también: observamos un strip-tease masculino, por ejemplo ("Sherezade", Pepe Carvalho).

8 ("Bosque del olvido 18:40 horas", Cuenta atrás, Piloto).

9 Fátima [tono escéptico]: "Como son yonquies son los asesinos, ¿verdad?" ("La virtud del asesino", Génesis, 1.8)

${ }^{10}$ Entendemos por Amber Alert la denominación de un periodista de The Guardian al fenómeno de que muchas series tengan como protagonista una mujer en posición de víctima. Denominó así el fenómeno a raíz del título de la enésima producción con dicho planteamiento (Amber Alert, 2012), además de ser la denominación de menores de edad desaparecidos en muchos países.

${ }^{11}$ Comisario a Petra: "Es usted uno de mis mejores hombres...mujeres...la mejor mujer, ya me entiende" (Petra Delicado).

${ }^{12}$ La serie Los misterios de Laura fue adaptada para la NBC (The Mysteries of Laura, 2014-2016).

${ }^{13}$ Forma parte de la caracterización del personaje, estar un poco al margen de la ley. No le preocupan asuntos como las plantaciones de marihuana; cierra casos para no "molestar" más a algunos implicados que han sufrido ("Bosque del olvido 18:40 horas", Cuenta atrás, Piloto); intercepta a Escobar aun cuando no tiene la jurisdicción para hacerlo (“Océano Atlántico, aguas jurisdiccionales de Togo, 07:14 horas”, Cuenta atrás, 1.2).

14 Ver Tous-Rovirosa $(2008,263)$.

${ }^{15}$ Pascual propone que su hija deje el Cuerpo tras una acción policial (El comisario). En la misma serie, el subinspector Lucas Aguilar (Fernando Andina) comenta ampliamente el hecho que su compañera lleve falda, impedimento para las persecuciones policiales

${ }^{16}$ En el episodio "Odio y amo" (Policías, 6.13), es Paula quien no duda en ponerle las esposas a Cipriano. Los agentes de ambos sexos participan de igual modo en la persecución del asesino de Juani y en la persecución del francotirador, por ejemplo.

17 Tema que aparece también en "Como una flor", piloto de Petra Delicado.

${ }^{18}$ Pope se enfrenta al representante de la asociación de vecinos porque insulta a una mujer negra en "Ojo por ojo", (El comisario, 1.6).

${ }^{19}$ Colectivo migrante retratado en un entorno particular, mediante una serie de tópicos. Son frecuentes las palizas, los abortos y el vudú ("Club Ipanema, 23.11 horas", Cuenta atrás, 1.6).

${ }^{20}$ En una persecución policial, un comerciante: "Putos negros, me quieren matar". Charlie: "Cállese ya, ijoder!" ("Cuatro balas", El comisario, 8.9).

${ }_{21}$ Petra llama "putita descarada" a una recepcionista por ser muy presumida ("Nadie, el asesino", Petra Delicado, 1.9).

${ }^{22}$ Fermín: "El violador podría haber elegido a otra víctima". Petra [cínica]: "Sí, a la hija de un obrero, que hace menos ruido" ("Como una flor", Petra Delicado, Piloto).

${ }^{23}$ Petra: "Como mejor se está es solo, sobre todo si uno ha conseguido desmitificar todas esas tonterías de la familia y los seres queridos" (“Dulce compañía”, Petra Delicado, 1.3). 
${ }^{24}$ Joserra: "Yo no podía con los maricas y estuve viviendo con mi primo y su amigo..."; "Necesitan a un par de machos en casa" (El comisario).

${ }^{25}$ Pascual: "Es maricón seguro" ("Sola en casa", El comisario, 9.5).

${ }^{26}$ El comisario Garrido, tras una detención: "Todo lo que tiene de grande lo tiene de mariquita" ("Regreso al pasado", La chica de ayer, 1.1).

27 Samuel: "No todos los gays son como tu crees que son, hay algunos que no hablan, que tienen dos vidas...". ("Vicente, el travestido", La chica de ayer, 1.5).

${ }^{28}$ Comandante Herrera a Pereira: "Aquí no se suele cuadrar nadie" (Soy el solitario).

${ }^{29}$ Mateo: "Esos [la Guardia Civil] no cambian" ("Los desastres de la guerra", Génesis, 1.1.).

${ }^{30}$ Alfredo: "Tu sigue con el ordenador, chaval, y deja que pensemos los mayores" (Soy el solitario). 